\title{
DESAIN DISKUSI MATEMATIKA YANG MENGUNTUNGKAN BAGI SISWA
}

\author{
Anwar Rifa'i \\ Universitas Negeri Yogyakarta
}

\section{INFO ARTICLES \\ Article History: \\ Received: 17 Agustus 2017 \\ Revised: 17 September 2017 \\ Approved: 15 Oktober 2017 \\ Publish Online: 5 November}

\section{Key Words:}

Pentingnya Diskusi Matematika, Desain Diskusi Matematika, Persiapan Diskusi, Peran Siswa, Peran Guru

\section{(C) (†) (?)} under a Creative Commons AttributionShareAlike 4.0 International License.

\begin{abstract}
The quality of discussion in the classroom is one of the important factors that determine the mathematics learning outcome. Mathematics discussion has been proven can help students to understand mathematics concepts (Goos, 1995; Lee, 2006). A good mathematical discussion will provide an opportunity for students to exchange ideas, develop communication skills, thinking skills, understanding of the concept and encourage the emergence of new ideas. In the other hand, there is other evidence which stated that the mathematics discussion does not always bring a positive impact on learning outcomes for mathematics (Shouse, 2001). Because of that, it is importat to know about the benefical mathematics discussion design for students. This article tries to present a favorable mathematics discussion design for students. 5 Best Practices for orchestrating Productive Discussions by NCTM became one of the foundations of this mathematics discussion design. Based on studies conducted, the mathenatics discussion design that is beneficial to students described in several parts: the preparation of the discussion, the role of teacher and also the role of students in mathematics discussion.
\end{abstract}

\begin{abstract}
Abstrak: Kualitas diskusi di dalam kelas adalah salah satu faktor penting yang menentukan hasil pembelajaran matematika yang dilakukan. Diskusi matematika telah terbukti mampu membantu siswa dalam memahami konsep matematika (Goos, 1995; Lee, 2006). Kualitas diskusi matematika yang baik akan memberikan kesempatan bagi siswa untuk saling bertukar ide, mengembangkan kemampuan komunikasi, kemampuan berpikir, pemahaman konsep dan mendorong timbulnya ide baru. Tetapi terdapat bukti lain yang menyatakan bahwa diskusi matematika tidak selalu membawa dampak positif pada hasil belajar matematika (Shouse, 2001). Oleh karena itu, munculah pemikiran yang mempertanyakan mengenai bagaimanakah desain diskusi yang menguntungkan bagi siswa. Tulisan ini berusaha untuk menyajikan desain diskusi matematika yang menguntungkan bagi siswa. 5 Practices for Orchestrating Productive Math Discussions menurut NCTM menjadi salah satu landasan penyusunan desain diskusi matematika ini. Berdasarkan kajian yang dilakukan desain diskusi yang menguntungkan bagi siswa diuraikan dalam beberapa bagian yaitu: persiapan diskusi, peranan guru dan juga peranan siswa dalam diskusi matematika.
\end{abstract}

C Correspondence Address: Jl. Colombo No.1, Karang Malang, Caturtunggal, Kec. Depok, Kabupaten Sleman, Daerah Istimewa Yogyakarta 55281; e-mail: anwar.rifaai@gmail.com

How to Cite (APA 6 $^{\text {th }}$ Style): Rifa'i. (2017). Desain Diskusi Matematika yang Menguntungkan Bagi Siswa. JKPM (Jurnal Kajian Pendidikan Matematika), 03(01), 59-66

Copyright: Rifa'i(s), (2017)

Competing Interests Disclosures: The authors declare that they have no significant competing financial, professional or personal interests that might have influenced the performance or presentation of the work described in this manuscript 


\section{PENDAHULUAN}

Pemahaman matematika terus berkembang melalui komunikasi matematika yang dilakukan baik dalam bentuk lisan maupun tulisan. Sampai sekarangpun konsep-konsep matematika bisa sampai kepada siswa melalui komunikasi yang dilakukan oleh guru kepada siswa atau melalui komunikasi tertulis dari refrensi yang dipelajari oleh siswa. Hal ini sejalan dengan pendapat Santos, Leonor \& Silvia Semana (2015:66) yang menyatakan bahwa komunikasi merupakan dimensi penting dalam perantara pembelajaran. Pentingnya komunikasi matematika untuk membentuk pemahaman matematika siswa menjadikannya sebagai salah satu aspek penting yang ditekankan dalam pembelajaran matematika di sekolah.

Dalam draft mathematics framework PISA 2015 (OECD, 2015:9) terdapat tiga komponen yang dianalisis pada proses matematika yaitu formulatig situations mathematically (2) Employing mathematical concepts, facts, procedures, and reasoning (3) Interpreting, applying and evaluating mathematical outcomes. Poin (1) dan (3) merujuk pada kemampuan komunikasi matematis yang harus dimiliki oleh siswa. Oleh karena itu, jika dilihat dari hasil tes PISA yang kurang memuaskan selama beberapa waktu terakhir dapat disimpulkan bahwa kemampuan komunikasi siswa di Indonesia juga masih belum optimal.

Diskusi dianggap sebagai sarana yang tepat untuk memfasilitasi komunikasi matematika, sehingga diskusi menjadi pilihan yang banyak diambil guru untuk mencapai pemahaman matematika yang diinginkan. Hal ini didukung oleh pendapat Goos (1995) dan Lee (2006) yang menyatakan bahwa diskusi matematika memiliki dampak yang positif terhadap kemampuam pemahaman matematika siswa.

Namun, terdapat penelitian yang menyatakan bahwa diskusi matematika tidak selalu memberikan dampak positif terhadap pencapaian hasil belajar matematika siswa (Shouse, 2001). Penelitian ini berimplikasi bahwa diskusi matematika juga tidak selalu bisa memberikan manfaat terhadap pemahaman matematika siswa. Dengan demikian munculah pemikiran yang mempertanyakan tentang bagaimana proses diskusi yang akan memberikan dampak positif bagi siswa terutama dalam hal membangun pemahaman matematikanya. Tulisan ini akan membahas mengenai desain diskusi matematika yang menguntungkan bagi siswa dalam proses pemahaman matematika.

\section{METODE}

Jenis dan metode penelitian dengan menggunakan metode penelitian kualitatif, dengan tujuan untuk memperoleh jawaban yang terkait dengan pendapat, tanggapan, persepsii atau uraian kata-kata. Deskriptif penelitian yang dipilih adalah jenis studi pustaka yang merupakan telaah dari literatur. Metode pengumpulan data dengan observasi. Sebagimana di sampaikan (Nazir, 2003) bahwa teknik pengumpulan data secara studi pustaka teknik simak dengan mengadakan studi penelahaan terhadap buku-buku literatur-literatur, catatancatatan, dan laporan-laporan yang ada hubungannya dengan masalah yang dipecahkan terkait pembuktian informal dalam pembelajaran matematika.

\section{PEMBAHASAN}

Dalam proses pembelajaran, diskusi merupakan salah satu pendekatan yang banyak diterapkan oleh guru. Hal ini dilakukan karena guru percaya bahwa dengan berdiskusi siswa akan mampu membangun pengetahuan matematikanya. Berdasarkan sebuah laporan, diskusi telah dijadikan sebagai alat dalam meningkatkan kemampuan nalar siswa di seluruh dunia (Yore, Bisanz \& Hand, 2003). Tidak dipungkiri, 
telah banyak peneliti yang membuktikan manfaat dari pendekatan diskusi termasuk dalam pembelajaran matematika. Seperti D'Ambrosio et al. (1995) yang menyatakan bahwa melibatkan siswa dalam diskusi matematika akan meningkatkan pemahaman siswa tentang matematika.

Menurut Bernard J. Oldfield, (1991:8) terdapat tiga alasan mengapa diskusi matematika penting bagi siswa. Yang pertama karena diskusi memberikan kesempatan kepada siswa untuk mengembangkan kemampuan komunikasinya. Menurut NCTM (2000) salah satu kemampuan yang harus dimiliki siswa adalah kemampuan komunikasi matematis. Hal ini mengindikasikan bahwa kemampuan komunikasi penting dalam proses pembelajaran matematika. Keterlibatan siswa dalam komunikasi matematika akan membantu meningkatkan pemahaman mereka tentang suatu konsep matematika. Dengan melakukan komunikasi matematika, baik itu secara lisan maupun tulisan siswa dapat merefleksikan gagasan matematika yang telah dimiliki. Selain itu, dalam proses komunikasi kemungkinan kesalahan konsep matematika bisa lebih mudah untuk diantisipasi.

Alasan yang kedua karena diskusi matematika dapat mengembangkan kemampuan berpikir matematis siswa. NCTM (2000) menyatakan bahwa salah satu standar komunikasi matematis adalah penekanan pengajaran matematika dalam mengorganisasi dan mengkonsolidasikan kemampuan berpikir matematis (mathematical thinking) siswa melalui komunikasi. Dengan demikian, selama proses diskusi berlangsung dengan baik maka siswa akan memiliki kemampuan berpikir matematis yang baik pula.

Selanjutnya, alasan ketiga mengapa diskusi matematika penting bagi siswa berkaitan dengan hubungan antara diskusi dan kemampuan pemahaman konsep siswa. Dalam NCTM (2000) disebutkan bahwa pemahaman konsep matematika adalah aspek penting dalam pembelajaran matematika. Pemahaman konsep matematika akan mendasari proses pemecahan masalah matematika maupun masalah sehari-hari siswa. Pemahaman konsep ini tidak bisa diberikan kepada siswa dengan paksaan. Sebaliknya, pemahaman matematika akan menjadi bermakna jika dibangun sendiri oleh siswa. Selama proses diskusi siswa saling bertukar pikiran sehingga proses pembangunan pemahaman matematika bisa berjalan dengan baik.

Dari sisi psikologi belajar, menurut Skemp (1971:121-122) manfaat dari diskusi matematika adalah terjadinya pertukaran ide dan mendorong munculnya ide baru. Ada banyak hal yang tidak cukup jika hanya dipikirkan, tetapi lebih daripada itu juga perlu untuk didiskusikan. Kegitan diskusi mampu membantu memeperjelas kata-kata atau simbol-simbol lain dalam matematika. Diskusi memungkinkan siswa untuk menyampaikan ide-idenya kepada siswa lain. Selain itu, selama proses diskusi siswa akan belajar untuk mendengarkan pendapat dari teman-temannya. Proses ini memungkinkan munculnya ide baru yang bisa jadi tidak akan diketahui tanpa adanya komunikasi dalam belajar matematika.

Berdasarkan uraian yang telah disampaikan dapat disimpulkan bahwa terdapat beberapa manfaat dari diskusi yang membuatnya menjadi penting untuk dilakukan selama proses pembelajaran matematika yaitu karena diskusi matematika mampu: mengembangkan kemampuan berpikir matematis siswa, mengembangkan kemampuan berpikir matematis siswa, mengembangkan kemampuan pemahaman konsep siswa, memfasilitasi pertukaran ide, dan mendorong munculnya ide-ide baru.

Diskusi matematika memiliki peranan penting dalam proses pembentukan dan pengembangan konsep matematika yang dimiliki oleh siswa. Namun, telah disebutkan sebelumnya bahwa diskusi matematika tidak selalu membawa dampak positif terhadap pemahaman konsep matematika siswa. Oleh karena itu, pelaksanaan diskusi matematika harus dikondisikan agar mampu memberikan hasil yang maksimal kepada siswa. Berikut ini adalah desain diskusi matematika yang diharapkan mampu memberikan keuntungan bagi siswa.

\section{Persiapan Sebelum Diskusi Dilakukan}

Persiapan yang matang akan menjadi kunci keberhasilan diskusi matematika yang dilakukan. Sebelum memulai diskusi guru perlu menyiapkan berbagai hal berkaitan dengan diskusi, mulai dari mempersiapkan 
tujuan diskusi hingga merancang proses yang akan dilalui selama diskusi. Tujuan diskusi penting karena menjadi penentu arah diskusi yang akan berlangsung. Rodney E. Mcnair (2000 : 200) menyatakan bahwa dalam sebuah diskusi matematika perlu adanya subjek matematika dan tujuan matematika. Subjek matematika meliputi, variablel, bentuk, ruang, menggeneralisasi pola dan juga hubungan diantara subjek itu. Sedangkan tujuan matematika berkaitan dengan hasil yang ingin dicapai dalam proses belajar matematika.

Pengaitan antara subjek dan tujuan matematika perlu dilakukan agar diskusi menjadi lebih menarik bagi siswa. Proses pengaitan ini berhubungan dengan konten materi yang perlu dipilih oleh guru. Menurut Pirie and Schwarzenberger (1988), and Lo et al. (1991) seberapa jauh keterkaitan antara tugas yang diberikan dengan siswa akan mempengaruhi bagaimana diskusi nantinya berlangsung. Akibatnya perlu dipilih konten materi yang dekat dengan kehidupan siswa. Dalam hal ini disarankan untuk memilih permasalahan kontekstual yang berhubungan langsung dengan siswa. Walaupun tidak menutup kemungkinan untuk menggunakan masalah non kontekstual yang tetap memiliki keterkaitan dengan siswa.

Permasalahan yang diberikan kepada siswa untuk diskusi juga harus memiliki level tertentu sesuai dengan kemampuan siswa dalam kelas yang akan melakukan diskusi. Permasalahan yang diajukan tidak boleh terlalu mudah namun juga tidak boleh terlalu sulit bagi siswa. Herman Hujodo (2003 : 149), menyatakan bahwa masalah bagi siswa harus memenuhi dua syarat yaitu : pertanyaan yang diberikan harus dapat dimengerti siswa, tetapi pertanyaan tersebut juga merupakan tantangan tersendiri bagi siswa dan pertanyaan yang diberikan tidak dapat dijawab dengan prosedur rutin yang biasa dilakukan siswa. Dengan demikian, guru perlu mengetahui terlebih dahulu kemampuan siswanya sebelum menentukan permasalahan apa yang akan disajikan dalam diskusi. Beberapa contoh topik permasalahan yang dirasa akan cocok untuk kegiatan diskusi matematika adalah pencarian pola, penemuan rumus dan juga pembuktian rumus matematika.

\section{Peranan Siswa dalam Diskusi Matematika}

Sikap siswa dalam pelaksanaan diskusi matematika akan dipengaruhi oleh kepercayaan (belief) mengenai matematika. Kepercayaan ini selanjutnya mempengaruhi kerangka matematika yang digunakan selama diskusi. Rodney E. Mcnair (2001 : 201) dalam tulisannya menyatakan tiga kerangka matematika yang sering digunakan di dalam kelas yaitu : system reasoning frame, calculation frame, problem frame. Dalam system reasoning frame, siswa mengembangkan proses matematika baru untuk mengorganisasi pengalamannya atau mereka akan melakukan refleksi pada organisasi, strategi, dan konsep yang telah dimiliki sebelumnya. Dengan demikian, siswa akan membangun konsep matematikanya sendiri dengan cara melakukan akomodasi dan asimilasi terhadap konsep baru yang diterimanya. Calculation frame akan mengarahkan siswa dalam mencari perhitungan yang sesuai dalam diskusi, sedangkan problem frame lebih terfokus pada masalah yang dihadirkan dalam diskusi. Dengan demikian, frame yang digunakan ini harus menyesuaikan dengan tujuan dari diskusi yang ingin dicapai.

Selanjutnya, Skemp (1971:123) menyatakan manfaat dari diskusi sangat dipengaruhi oleh hubungan antara anggota kelompok. Dalam hal ini siswa disarankan untuk bisa saling bertoleransi terhadap pendapat yang disampaikan oleh anggota kelompok yang lain. Walaupun bukan berarti bahwa siswa harus menerima semua ide yang disampaikan oleh anggota lain. Hanya saja dalam menanggapi ide yang disampaikan oleh anggota lain, siswa tidak boleh melakukannya secara berlebihan. Cara penyampaian perbedaan pendapat ini harus dilakukan sesuai aturan kelompok yang sudah ada dalam kelompok. Dengan kata lain, diskusi yang dilakukan harus berdasarkan alasan yang masuk akal. Kemudian pada akhir diskusi, diharapkan semua anggota kelompok bisa menerima hasil keputusan bersama yang telah disepakati.

Peranan siswa merupakan inti dari diskusi matematika yang dilakuakan. Cara berpikir siswa mengenai matematika dan juga kemampuan sosial yang dimiliki mereka akan sangat berpengaruh dalam keberhasilan diskusi yang dilakukan. Untuk mencapai hasil diskusi yang maksimal, siswa dituntut mampu mengelola 
kedua kemampuan ini dengan baik. Selanjutnya, dalam proses pelaksanaan peran siswa yang diharapkan, perlu keterlibatan dari guru. Hal ini disebabkan belum tentu semua siswa memiliki sikap dewasa yang diperlukan dalam berdiskusi.

\section{Peranan Guru dalam Diskusi Matematika}

Skemp (1971:124) menyatakan bahwa, idealnya guru bertindak layaknya seorang mayor dalam militer dan konduktor dalam sebuah orkestra yang sangat berhari-hati dalam memainkan peranannya. Guru sebaiknya memposisikan dirinya dengan baik agar fungsinya dalam menfasilitasi siswa bisa berjalan tanpa terlalu ikut campur dalam diskusi yang dilakukan oleh siswa. Guru juga perlu mengatur diskusi dengan memberikan perintah yang jelas serta batasan waktu yang jelas dalam diskusi. Lebih lanjut Skemp memberikan ilustrasi mengenai peran guru di dalam kelas. Jika selama proses diskusi terdapat siswa yang melakukan kesalahan dalam menjawab pertanyaan maka guru menuliskan kesalahan jawaban siswa itu di depan kelas. Kemudian guru memberikan pertanyaan yang mengarahkan seluruh siswa untuk tidak hanya mencari jawaban yang lebih tepat namun juga belajar dari kesalahan yang ada. Hal ini akan membuat siswa yang melakukan kesalahan tidak merasa malu dan juga membuat siswa lain yang juga belum paham menjadi mengerti mengenai kesalahan yang dilakukan.

Menurut Margaret S. Smith \& Mary Kay Stein (2011:7-8) terdapat 5 praktik untuk menyusun diskusi matematika yang produktif (5 Practices for Orchestrating Productive Math Discussions). Kelima praktik ini mengarahkan guru dalam mengambil tindakan yang perlu dilakukan untuk memfasilitasi diskusi matematika. Praktik-praktik ini antara lain adalah anticipating, monitoring, selecting, sequencing, dan juga connecting. Lima praktik ini diharapkan mampu memberikan kesempatan pada guru dalam menggunakan respon siswa untuk meningkatkan pemahaman matematika mereka. Berikut penjelasan mengenai kelima praktik tersebut.

\section{a. Anticipating}

Mengantisipasi masalah yang akan timbul dalam diskusi perlu dilakukan oleh guru. Tanpa adanya antisipasi, akan terdapat banyak kesalahan yang tidak terelakkan, sehingga mungkin saja proses diskusi tidak akan mencapai hasil yang diingikan. Mengantisipasi kemungkinan dimana siswa akan mengalami kesulitan dan memiliki alternatif pemecahannya akan membantu guru dalam memberikan skafolding yang tepat waktu dan tepat cara. Dengan demikian, siswa akan lebih cepat kembali pada jalur pembentukan konsep matematika yang benar. Untuk melakukan praktik yang pertama ini, guru perlu melakukan beberapa hal. Seperti yang telah disampaikan dalam bagian persiapan, guru perlu menyiapkan masalah yang sesuai untuk diskusi. Sebaiknya guru mengerjakan permasalahan yang akan diberikan kepada siswa terlebih dahulu untuk mengetahui kemungkinan kesalahan yang akan dilakukan siswa selama proses pemecahan masalah. Selain itu guru juga perlu mengetahui hasil seperti apa yang diharapkan diperoleh oleh siswa.

\section{b. Monitoring}

Selama siswa melakukan diskusi, diharapkan guru juga aktif. Dengan melaksanakan diskusi matematika di dalam kelas, bukan berarti guru menyerahkan sepenuhnya pembelajaran kepada siswa. Norris \& Phillips (2003), menyatakan bahwa sebuah diskusi membutuhkan skaffolding untuk mendukung proses belajar yang berlangsung. Dalam proses ini, guru bisa berkeliling untuk melakukan observasi mengenai strategi yang digunakan siswa dalam menghadapi masalah. Selanjutnya, guru perlu membuka mata dan telinganya untuk lebih peka terhadap permasalahan yang dihadapi oleh siswa. Dengan demikian, skafolding bisa diberikan secara tepat cara, tepat waktu dan tepat sasaran. Pemberian bantuan kepada siswa ini perlu dilakukan melalui pertanyaan-pertanyaan agar siswa kembali pada jalur yang benar atau berpikir secara lebih mendalam. Membuat catatan mengenai cara siswa mengomunikasikan idenya dan mengenai masalah yang menantang 
bagi siswa atau masalah yang terlalu mudah akan membantu guru dalam menlaksanakan diskusi yang lebih baik pada pertemuan berikutnya.

\section{c. Selecting}

Praktik ini merupakan bagian yang cukup krusial dalam proses diskusi matematika. Saat sudah kembali pada diskusi kelas, memilih siswa secara random untuk menjelaskan hasil pekerjaannya tidak akan memberikan hasil yang produktif dalam pembangunan konsep siswa. Pemilihan ini perlu memperhatikan mengenai apa yang ingin ditekankan oleh guru. Sebagai contoh, memilih dua siswa yang menggunakan strategi yang setipe bisa mengurangi kemungkinan munculnya pembandingan perbedaan strategi pemecahan masalah yang digunakan. Pemilihan ini juga akan membuat keduanya saling melengkapi dan mendukung ide satu sama lain. Walaupun selama proses diskusi, perbedaan sebenarnya justru menguntungkan karena akan memancing lebih banyak komunikasi matematika.

\section{d. Sequencing}

Pada tahap ini guru perlu mempertimbangkan bagaimana siswa akan menampilkan hasil pekerjaanya. Guru perlu merancang bagaimana langkah konkrit yang akan dilakukan oleh siswa dalam penyajian hasil kerja dan juga bagaimana urutan hasil kerja yang akan ditampilkan. Langkah konkrit penyajian hasil kerja yang dimaksud di sini adalah cara teknis penyajian hasil kerja oleh siswa, misalnya apakah siswa akan menuliskannya secara langsung di papan tulis atau hanya perlu menyampaikannya secara oral di depan kelas. Kemudian urutan penampilan hasil kerja yang dimaksud berkaitan dengan penekanan yang ingin dibuat oleh guru. Penekanan ini bisa dimulai dari penampilan kesalahan konsep yang dilakukan oleh siswa ataupun dengan cara yang lain sehingga, diharapkan pemahaman konsep matematika siswa akan lebih optimal.

\section{e. Connecting}

Praktik menghubungkan konsep merupakan inti dari proses diskusi yang dilakukan. Pada tahap ini konsep baru yang didapatkan akan tersusun seacara lebih rapi di benak siswa. Oleh karena itu, ketrampilan guru dalam memfasilitasinya juga sangat penting. Untuk memandu penghubungan konsep matematika, guru harus memiliki ketrampilan dalam membuat pertanyaan yang memperjelas konsep matematika bagi siswa. Pancingan pertanyaan perlu diberikan untuk memandu siswa mencapai konsep matematika yang diinginkan. Dalam membantu proses menghubungkan, guru juga perlu membandingkan dua atau tiga hasil pekerjaan siswa baik itu mengenai persamaan maupun perbedaan yang ada, sehingga siswa akan memiliki gambaran yang lebih jelas mengenai hubungan konsep yang mereka dapatkan. Selain itu, pengaitan antara hasil ataupun proses yang dilakukan siswa dalam pekerjaanya dengan konsep yang sudah dimiliki sebelumnya juga perlu mendapatkan perhatian dari guru.

Dengan demikian, untuk mencapai hasil pembelajaran yang maksimal maka selama proses diskusi berlangsung, guru diharapkan mampu memaikan perannya dengan baik. Guru perlu mengetahui kapan pemberian bantuan yang tepat kepada siswa. Guru juga diharapkan mampu untuk memposisikan dirinya sebagai pemimpin diskusi di dalam kelas. Dalam menjalankan fungsinya ini, terdapat alternatif praktik yang bisa dilakukan yaitu anticipating, monitoring, selecting, sequencing, dan juga connecting.

\section{SIMPULAN}

Diskusi matematika telah terbukti memiliki dampak positif terhadap kemampuan pemahaman konsep matematika siswa. Namun terdapat penelitian yang menunjukkan bahwa diskusi matematika tidak selalau membawa dampak positif terhadap pemahaman siswa. Diskusi matematika sendiri memiliki banyak manfaat bagi siswa misalnya memfasilitasi siswa untuk bertukar ide, mengembangkan kemampuan komunikasi, 
kemampuan berpikir, pemahaman konsep dan membentuk ide-ide baru. Manfaat dari diskusi matematika akan tercapai jika kualitas dari diskusi itu baik. Desain diskusi berkualitas yang diharapkan akan menguntungkan bagi siswa merupakan perpaduan antara persiapan yang matang, peranan guru dan juga peranan siswa yang terkondisikan dengan baik.

\section{DAFTAR PUSTAKA}

D’Ambrosio, B., Johnson, H., \& Hobbs, L. 1995. Strategies for increasing achievement in mathematics. In R.W. Cole (Ed.), Educating everybody's children: Diverse teaching strategies for diverse learners $(121-138)$

Goos, M. 1995. How do you know when you understand? Using explanation to monitor and construct mathematical understanding. Paper presented at the Postgraduate Research Conference Commemorating 50 Years of Educational Studies at the University of Queensland, Brisbane, Queensland, Australia.

Herman Hudojo. 2001. Pengembangan Kurikulum dan Pembelajaran Matematika. Malang : JICA Universitas Negeri Malang.

Lee, C. 2006. Language for learning mathematics: Assessment for learning in practice. New York: Open University Press.

Mcnair, Rodney E. (2000). Working In The Mathematics Frame: Maximizing The Potential to Learn From Students' Mathematics Classroom Discussions. Educational Studies in Mathematics 42 : 197-209.

National Council of Teachers of Mathematics [NCTM] (2000), Curriculum and evaluation standards for school mathematics, National Council of Teachers of Mathematics, Reston, VA.

Norris, S.P., \& Phillips, L.M. 2003. How literacy in its fundamental sense is central to scientific literacy. Science Education, 87, 224-240.

OECD.(2015). PISA 2015 draft Mahematics Framework. diakses dari https://www.oecd.org/pisa/pisaproducts/Draft\%20PISA\%202015\%20Mathematics\%20Framework \%20.pdf pada tanggal 10 Januari 2017.

Oldfield, Bernard J. 1991. Games to Stimulate Mathematics Discussion. Journal Them Mathematical Association.Hlm 7-9.

Pirie, S.E.B. and Schwarzenberger, L.E.: 1988. Mathematical Discussion and mathematical understanding. Educational Studies in mathematics, 19, 459-470.

Santos Leonor, Silvia Semana. 2015. Developing mathematics written communication through expository writing supported by assessment strategies. Journal Education Studies Mathematics, 88, 65-87.

Shouse, R. 2001. The impact of traditional and reform-style practices on students mathematical achievement. In T. Loveless (Ed.), The Great Curriculum Debate: How Should We Teach Reading and Math?. Washington, D.C.: Brookings Institution Press.

Skemp, Richard R. 1971. Psychologi of Learning Mathematics. Australia : The Chaucer Press. 
66 Rifa'l

Smith, Margaret S \& Mary Kay Stein. 2011. 5 Practices for Orchestrating Productive Mathematics Discussions. United States of America : National Council of Mathematics.

Yore, L.D., Bisanz, G.L., \& Hand, B.M. 2003. Examining the literacy component of science literacy:

25 years of language arts and science research. International Journal of Science Education, $25,689-725$. 